\title{
THERMOCATALYTIC REMOVAL OF CARBONACEOUS MATERIALS
}

\author{
Z. Sarbak ${ }^{*}$ and K. Surma \\ Laboratory of Adsorption and Catalysis in Environmental Protection, Faculty of Chemistry, Adam Mickiewicz University, \\ Grunwaldzka 6, 60-780 Poznań, Poland
}

\begin{abstract}
Decomposition and removal of carbonizate was performed over platinum catalysts supported on two types of alumina differing in the surface area: low surface area one (LSA) and high surface one (HSA). For the sake of comparison, the performance of platinum catalyst supported on silica and bimetallic platinum-rhenium catalysts was analyzed. It has been shown that all platinum catalysts examined caused an increase in the removal of carbonizate. The activity of these catalysts was independent of the kind of support applied or addition of rhenium as a second component.
\end{abstract}

Keywords: carbonizate, catalysts, DTA/TG, oxidation

\section{Introduction}

The construction of a Diesel engine differs significantly from that of the engine with spark ignition, requires a different fuel and a different air to the fuel ratio as well as a higher pressure and temperature. In the presently available Diesel engines these parameters change in a wide range, therefore, the composition of exhaust gas from such engines is also different and complex. It is a result of a series of chemical and physical processes leading to formation of solid particles called the Diesel soot $[1,2]$. The particles of the Diesel soot on their porous surface strongly adsorb some of the fuel pyrolysis products including oligo- and polyaromatic hydrocarbons. Because of strong carcinogenic and mutagenic activity these hydrocarbons must be removed from the exhaust gases. One of the methods of decreasing the concentration of Diesel soot is the exhaust gas purification by filtering followed by catalytic oxidation, using air $[3,4]$. In our studies we use carbonizate which can simulate in some extend Diesel soot.

\section{Experimental}

The subjects of this study were platinum catalysts supported at three different concentrations on $\mathrm{Al}_{2} \mathrm{O}_{3}$ (Degussa C) of the low $\left(93 \mathrm{~m}^{2} \mathrm{~g}^{-1}\right)$ and (Norton) $\left(251 \mathrm{~m}^{2} \mathrm{~g}^{-1}\right)$ high surface area and on $\mathrm{SiO}_{2}(\mathrm{Cab}-\mathrm{O}-\mathrm{Sil})$ of the surface area $188 \mathrm{~m}^{2} \mathrm{~g}^{-1}$. The catalytic activity was measured by the area of the exothermal effects on the DTA (differential thermal analysis) curves of the samples studied. The study was performed on a carbonizate containing $78.64 \mathrm{C}, 1.34 \mathrm{H}$ and $1.7 \mathrm{~N}$ mass\% used to simulate the Diesel soot. The samples were tested in the airflow $\left(30 \mathrm{~mL} \mathrm{~min}^{-1}\right)$ in a derivatograph OD-102. A mixture of the catalyst with the carbonizate was heated at a rate of $13^{\circ} \mathrm{C} \min ^{-1}$ to a temperature $1000^{\circ} \mathrm{C}[5]$.

\section{Results and discussion}

Table 1 presents the data illustrating catalytic activity of the platinum catalysts samples studied in the reaction of carbonizate removal. As follows from the data, the support (two types of alumina one with low surface area (LSA) and second one with high surface area (HSA)) does not show any catalytic activity. Introduction of platinum on the support causes a significant increase in the catalytic activity, as indicated by a decrease in the mass of the carbonizate. Moreover, with increasing content of platinum on the support the catalytic activity increases. The type of support $\left(\mathrm{Al}_{2} \mathrm{O}_{3}\right.$ and

Table 1 Catalytic activity of supported Pt catalysts in oxidation of carbonizate

\begin{tabular}{lc}
\hline Catalyst & $\begin{array}{c}\text { Activity } \\
\text { (carbonizate mass/\%) }\end{array}$ \\
\hline $\mathrm{Al}_{2} \mathrm{O}_{3}(\mathrm{LSA})$ & 0 \\
$0.3 \mathrm{mass} \% \mathrm{Pt} / \mathrm{Al}_{2} \mathrm{O}_{3}(\mathrm{LSA})$ & 25 \\
$3.0 \mathrm{mass} \% \mathrm{Pt} / \mathrm{Al}_{2} \mathrm{O}_{3}$ (LSA) & 28 \\
$9.0 \mathrm{mass} \% \mathrm{Pt} / \mathrm{Al}_{2} \mathrm{O}_{3}$ (LSA) & 39 \\
$3.0 \mathrm{mass} \% \mathrm{Pt} / \mathrm{Al}_{2} \mathrm{O}_{3}$ (HSA) & 29 \\
$3.0 \mathrm{mass} \% \mathrm{Pt} / \mathrm{SiO}_{2}$ & 30 \\
3 mass $\% \mathrm{Pt}+3$ mass $\%$ Re/Al $\mathrm{O}_{3}$ (LSA) & 26 \\
\hline \multicolumn{2}{c}{$\mathrm{LSA}-$ low surface area, $\mathrm{HSA}-$ high surface area }
\end{tabular}

* Author for correspondence: sarbak@amu.edu.pl 
$\mathrm{SiO}_{2}$ ) and their surface area have no significant effect on the catalytic activity. Interestingly, an addition of another metal component (Re) to platinum does not result in increased catalytic activity.

However, as follows from the differences in the shape of the DTA and TG curves, the catalysts studied have different effect on the course of processes taking place on increasing temperature of the reaction. For the sample of sole carbonizate subjected to heating the DTA curve shows a single distinct exothermal effect with a maximum at $445^{\circ} \mathrm{C}$ and one small exothermal effect broadened over the temperature range $519-618^{\circ} \mathrm{C}$. As mentioned above, alumina alone is not active in the oxidation reaction but it is responsible for significant changes in the composition of carbonisate. The DTA/TG curves recorded in the presence of alumina (Fig. 1) differ considerably from those recorded for carbonisate alone (Fig. 1). The DTA curve obtained for the sample of the carbonisate in the presence of alumina (rys.1) reveals a single endothermic effect with a maximum at $542^{\circ} \mathrm{C}$ with two clearly marked inflection points on the declining branch of the DTA curve at 592 and $692^{\circ} \mathrm{C}$. This character of the DTA curve means

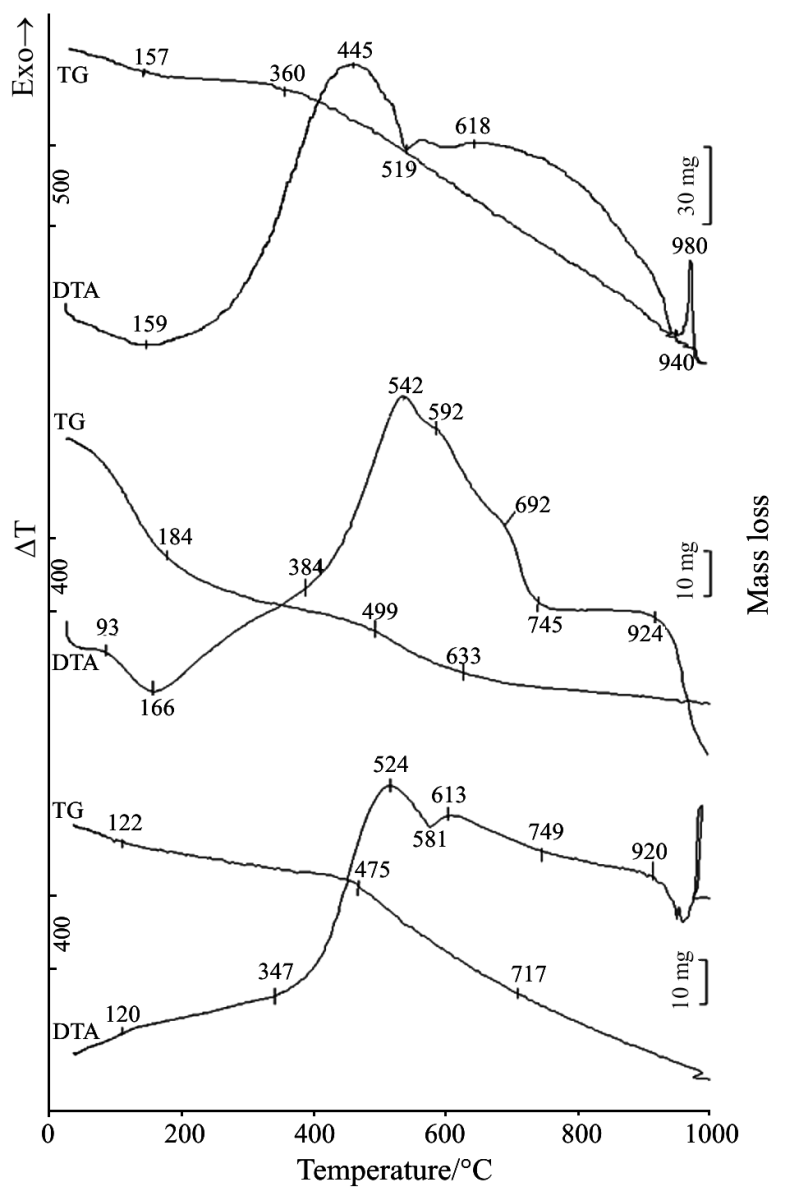

Fig. 1 DTA/TG curves of upper - carbonizate, middle $-\mathrm{Al}_{2} \mathrm{O}_{3}$ and bottom -3.0 mass $\% \mathrm{Pt}+3.0$ mass $\% \mathrm{Re} / \mathrm{Al}_{2} \mathrm{O}_{3}$ catalyst that some of the carbonizate components undergo transformation into components that do not undergo further thermocatalytic removal.

The next series of experiments was undertaken to study the effect of the type of support on the activity of the catalysts containing 3.0 mass $\%$ platinum. Figure 2 presents the course of the DTA and TG curves. The character of these curves recorded for the catalysts supported on LSA and HSA alumina samples and on silica is very similar. The DTA curves show two distinct maxima at $529-539$ and $611-615^{\circ} \mathrm{C}$, therefore, it can be concluded that the type of support has no important effect on the number of carbonizate components and on the activity of catalysts in its removal. Moreover, it has been shown that increasing concentration of platinum introduced onto the support (Fig. 3) does not cause significant changes in the number of the carbonizate components as the DTA curve reveals only two distinct exothermic effects in close temperature ranges of 531-539 and $611-628^{\circ} \mathrm{C}$, respectively. The introduction of rhenium as second metal component - besides platinum (Fig. 1) does not bring about significant changes in the position of the exothermic effects, which means that the

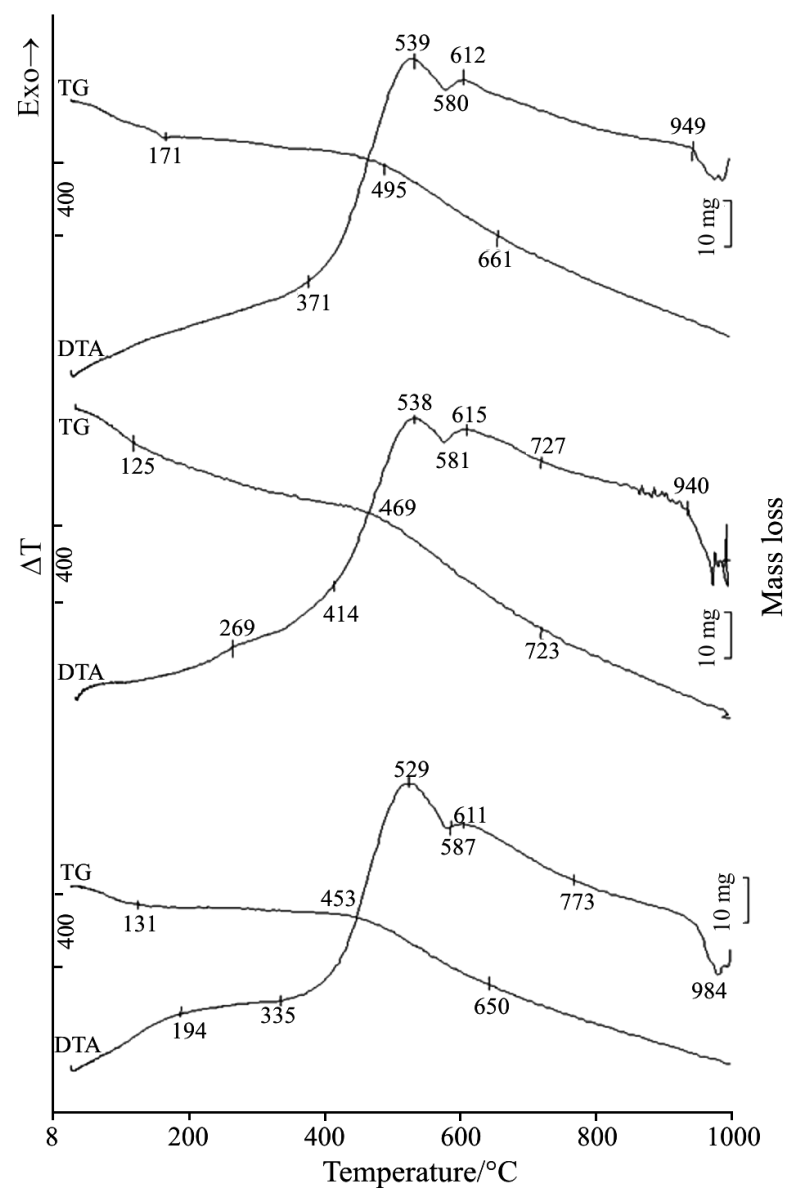

Fig. 2 DTA/TG curves of 3.0 mass $\%$ Pt catalysts supported on upper $-\mathrm{Al}_{2} \mathrm{O}_{3}-\mathrm{LSA}$, middle $-\mathrm{Al}_{2} \mathrm{O}_{3}-\mathrm{HSA}$ and bottom $-\mathrm{SiO}_{2}$ 


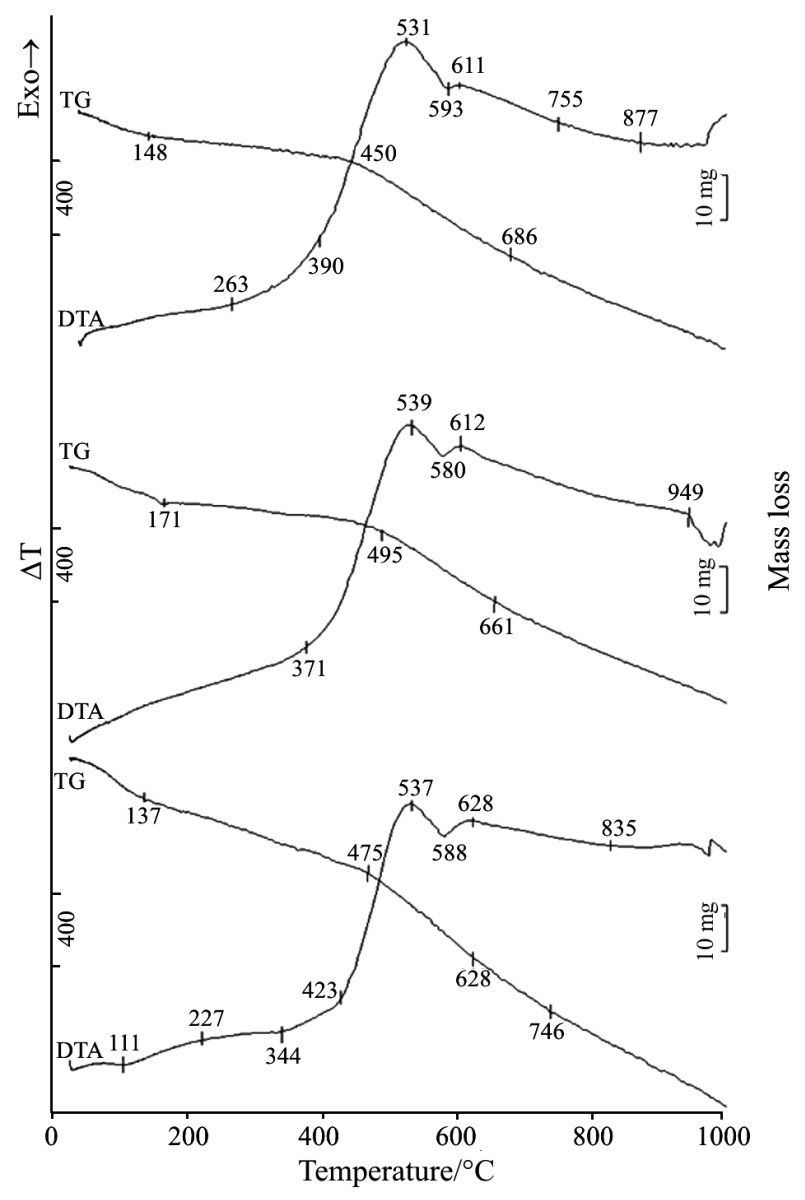

Fig. 3 DTA/TG curves of $\mathrm{Pt} / \mathrm{Al}_{2} \mathrm{O}_{3}$ catalysts: upper -0.3 mass $\%$, middle -3.0 mass $\%$ and bottom -9.0 mass $\%$

addition of rhenium does not affect the removal of the components assigned to the exothermic effect maximum at the temperatures higher than those appearing on the curves recorded on the thermal removal of the carbonizate. According to our previous results [6] based on $\mathrm{CO}$ chemisorption and FTIR examination we postulated that the main active centres on the $\mathrm{Al}_{2} \mathrm{O}_{3}$ (HSA) support were $\mathrm{Pt}^{\circ}$ atoms, whereas $\mathrm{Pt}^{\delta+}(\delta<1)$ and $\mathrm{Pt}^{\mathrm{m}+}$ $(2 \geq m>1)$ centres were also present on $\mathrm{Al}_{2} \mathrm{O}_{3}$ (LSA). The strong adsorption centres on $\mathrm{Pt} / \mathrm{SiO}_{2}$ samples were $\mathrm{Pt}^{\circ}$ atoms and $\mathrm{Pt}^{\delta+}$ ions. Therefore we can suggest that the metallic platinum are the main catalytic centres for removal of carbonaceous.

\section{Conclusions}

It has been shown that the introduction of 0.3 mass $\%$ platinum onto $\mathrm{Al}_{2} \mathrm{O}_{3}$ (LSA) causes a significant increase in the catalyst activity in the carbonizate removal in comparison to the removal without the catalyst or removal in the presence of $\mathrm{Al}_{2} \mathrm{O}_{3}$ alone. An increase in the platinum concentration in the catalyst causes a significant increase in the removal of the carbonizate. Moreover, the type of $\mathrm{Al}_{2} \mathrm{O}_{3}$ supports and their surface area (LSA and HSA) have no significant no effect on the catalytic activity. A similar result has been obtained for the platinum catalyst supported on $\mathrm{SiO}_{2}$. No changes in the activity of the sample $\mathrm{Pt}+\mathrm{Re} / \mathrm{Al}_{2} \mathrm{O}_{3}$ have been also observed compare to sample with platinum only. We can suggest that the metallic platinum are responsible for removal of carbonaceous deposit.

Analysis of the positions of the exothermic effects in the DTA of the carbonizate before and after the catalytic reaction indicates a removal of all its components, especially those assigned to the exothermal effects in temperatures up to $520^{\circ} \mathrm{C}$.

\section{References}

1 J. Neeft, Ph.D. Thesis, Catalytic oxidation of soot, Technische Universiteit Delft 1995.

2 Z. Sarbak, 'Kataliza w Ochronie Środowiska', (Catalysis in Environmental Protection) Wyd. Naukowe UAM, Poznań 2004.

3 Z. Sarbak, Przem. Chem., 83 (2003) 152.

4 Z. Sarbak and K. Surma, Principles and Methods for Accelerated Catalysts Design and Testing,

(Eds E. G. Derouane et al.), Kluwer Academic Publisher, Dordrecht 2002, p. 423.

5 Z. Sarbak and K. Surma, J. Therm. Anal. Cal., 72 (2003) 159.

6 Z. Sarbak, Adsorption Sci. Technol., 20 (2002) 347.

Received: February 10, 2005

In revised form: June 13, 2005

DOI: $10.1007 / \mathrm{s} 10973-005-6956-5$ 